\title{
ANTIBIOTICS SENSITIVITY TO THE PATIENTS WITH URINARY TRACT INFECTION IN PROF. DR. W. Z. JOHANNES HOSPITAL
}

\author{
MARIA HILARIA*, ELISMA, NI NYOMAN YULIANI, SAGABULANG M \\ Study Program of Pharmacy Health Polytechnic of Kupang, Indonesia. \\ Email: mariahilaria023@gmail.com
}

Received: 07 March 2018, Revised and Accepted:25 March 2018

\section{ABSTRACT}

Objective: The objectives of this research were to know antibiotic given to patients with UTI as well as to know the percentage of antibiotic sensitivity to each bacteria causing UTI in RSUD Prof. Dr. W. Z. Johannes Kupang during January 2013-December 2013.

Methods: This was a retroprospective hospital-based study conducted in collaboration with Microbiology Department in Prof. Dr. W.Z. Yohanes Hospital, Kupang, from January 2013 to December 2013. In the prior study, it was obtained data of patients with UTI that their urine cultured in Bacteriology Laboratory, RSUD Prof. Dr. W. Z. Johannes Kupang. Based on data of patients which have microbe and sensitivity test result, then it would be obtained the distribution of microbe or germ type, antibiotic sensitivity, and resistance. After that, it was conducted by data analysis.

Results: Among 87 respondents, 34.5\% were males and 65.5\% were females. The most widely used antibiotic is ciprofloxacin (98.8\%). The most sensitive antibiotic is meropenem (93.98\%) to the Escherichia coli, Klebsiella pneumonia, and Enterobacteriaceae group bacteria. The most resistance antibiotic is ampicillin (87.14\%).

Conclusion: UTI patients are more common in women compared with men. That germ most commonly found in UTI patients is E. coli. Meropenem was sensitive to all bacterias, while ampicillin was resistance.

Keywords: Urinary tract infections, Antimicrobials resistance, Sensitivity.

(c) 2018 The Authors. Published by Innovare Academic Sciences Pvt Ltd. This is an open access article under the CC BY license (http://creativecommons. org/licenses/by/4. 0/) DOI: http://dx.doi.org/10.22159/ajpcr.2018.v11s1.26599

\section{INTRODUCTION}

Infection disease is still one of the largest problems of health, in which it is not only in Indonesia but also in the worldwide. Despite virus as its cause, bacteria also play important role in causing infection disease. Infection case is getting increased and the causes is not only one microbe. This is what will result in difficulties in overcoming infection disease such as urinary tract infection (UTI) [1].

UTI case in Indonesia is still quite high. This condition cannot be separated from Indonesian population's health level that still far from standard and uneven or imbalance socioeconomic level, after all, affected directly to the UTI case in Indonesia [2]. The prevalence of UTI is varied based on age and gender. Prevalence to the female is larger than male. Ideally, antibiotic selected for UTI reaches a high concentration in urine and adsorbed well in oral giving. However, it should be given as with category and infection type suffered by patients. To prevent infection relapse, it is necessary to conduct continual medication. Then, it can raise new problem, which is the improvement of bacteria resistance causing UTI to the certain antibiotic, thus it may decrease ongoing therapy effectiveness [2]

Overused and misused antibiotic may also improve the development of antibiotic resistance. By resistance improvement to the antibiotic, then it will result in long duration to treat patients, more costs, and higher mortality number [1]. Bacteria resistance is the main problem in the health world. Based on the World Health Organization (WHO) in 2009, high cases of antibiotic resistance in Indonesia are quite worrying. Moreover, Indonesia placed in $8^{\text {th }}$ rank from 27 countries with a high load of medicinal invulnerability to the germs or microbes (multidrug resistance) in the world (Suara Pembaruan, March $23^{\text {th }}, 2014$ ). Bacteria resistance may cause failure in infection disease treatment. Main mechanism from bacteria resistance is inactivation of antibiotic agent by enzyme produced by bacteria and target alteration of antibiotic; thus, it will weaken antibiotic effect and decrease permeability to the antibiotic so that it can reach effective antibiotic concentration against bacteria and actively excluding antibiotic agent [3]

The principle of UTI treatment is bacteria eradication using antibiotic. Therapy target in UTI is microorganism causing infection. Therefore, UTI medication or treatment mostly uses antibiotic. Antibiotic selection to treat the infection is based on severity level, infection level, and microorganism type causing infection [4]. Antibiotics are widely used to treat diseases caused by bacterial infections. In the treatment of infectious diseases with antibiotics should be use the selection of appropriate class of antibiotics [3]. To choose the right antibiotic need to know the level of bacterial resistance to certain antibiotics, by looking at the results of antibiotic sensitivity test against bacteria. The result of the sensitivitas test is used as the guidance of the physician in the management of the infectious patient both in private practice, other health service, and hospital [3].

Hospital is a place with the largest use of antibiotic, for example, RSUD (Regional Public Hospital) Prof Dr. W. Z. Johannes Kupang. RSUD Prof Dr. W. Z. Johannes Kupang is the largest reference hospital in East Nusa Tenggara (NTT). The hospital has quite high antibiotic use and this hospital also able to conduct antibiotic sensitivity test.

However, it needs more supports and pharmaceutical or pharmacist workers in Pharmaceutical and Therapy Committee, especially related to antibiotic use controlling. It can be conducted through a selection of antibiotic type that will be inserted in antibiotic use guidance, formulation, and formulation, and tested its sensitivity [5]. Antibiotic sensitivity test is necessary to be conducted due to sensitivity test which is a method to determine bacteria vulnerability level to the antibiotic.

The objectives of this research were to know antibiotic given to patients with UTI as well as to know the percentage of antibiotic sensitivity to each bacteria causing UTI in RSUD Prof. Dr. W. Z. Johannes Kupang 
during January 2013-December 2013.

\section{METHODS}

\section{Research design}

The research was descriptive research to the secondary data that has been conducted in Bacteriology Laboratory, RSUD Prof. Dr.W.Z. Johannes Kupang.

\section{Population}

The research population was all registration records of patients with UTI that their urine cultured in Bacteriology Laboratory, RSUD Prof. Dr. W. Z. Johannes Kupang and has sensitivity in a period of January 2013-December 2013.

\section{Sample}

The sample in this research was registration record of a patient with UTI that the urine cultured in Bacteriology Laboratory, RSUD Prof. Dr. W. Z. Johannes Kupang and has sensitivity in a period of January 2013-December 2013.

\section{Inclusion criteria}

Inclusion criteria in this research were registration records of patients with UTI, received antibiotic, and have sensitivity test result, while exclusion criteria in this research were registration records of patients with UTI, received antibiotic, and have no sensitivity test result as well as incomplete and unreadable patient registration records also unclear and unreadable sensitivity test result.

\section{Data collection method}

In the prior study, it was obtained data of patients with UTI that their urine cultured in Bacteriology Laboratory, RSUD Prof. Dr. W. Z. Johannes Kupang during 2013. Based on patient registration number, obtained patient name, registration number, and select patients who use antibiotics which have microbial test results and its sensitivity. Incomplete, unreadable data, and no microbe and sensitivity test result were excluded from this research. Based on data of patients that have microbe and sensitivity test result, then it would be obtained the distribution of microbe or germ type, antibiotic sensitivity, and resistance. After that, it was conducted by data analysis.

\section{RESULT}

Based on the obtained data from registration records, the result of urine culture and sensitivity test in 2013 (January-December) was 102 patients. From those 102 patients, it was conducted by urine culture and obtained 87 patients with positive UTI.

From Table 1, it shows data based on gender where female (65.5\%) has a larger risk of UTI than male (34.5\%). based on age, most of patients with positive UTI in period of January 2013 to December 2013 were patients with age of 31-40 years old as much as 15 patients consist of 4 males and 11 females (Fig. 1).

Based on Graph in Fig. 2, it shows that antibiotic that mostly used as antibiotic sensitivity test is ciprofloxacin $(98.8 \%)$. The most sensitive antibiotic is meropenem (93.98\%), followed by clindamycin $(80.0 \%)$, erythromycin $(66.67 \%)$, amoxicillin $(65.38 \%)$, gentamicin $(60.98 \%)$, ceftazidime (54.88\%), chloramphenicol $(47.27 \%)$, ciprofloxacin (45.35\%), ceftriaxone (31.75\%), sulfamethoxazole (25.81\%), penicillin dan cefoxitin masing-masing (25.0\%), tetracycline (23.64\%), and ampicillin (10.0\%), respectively.

\section{DISCUSSION}

If it is seen based on gender, then female has higher risk toward UTI than male. Based on patient age, young women are more susceptible to UTIs (Table 1). UTI more frequently occurs in female. One of the causes is shorter female urethra so that contaminant bacteria easier to get access to the urinary. Other factor that cause in deteriorating UTI in females is urethra irritation to females during intercourse.
Short urethra will increase the possibility of microorganism to stick on urethra hole during intercourse which than has access to urinary [6].

From Table 2, it shows that from urine culture, the most frequent bacteria found are Escherichia coli (35.5\%), the second is Enterobacteriaceae group (18.8\%), followed by Klebsiella pneumoniae (13.3\%), Pseudomonas aeruginosa (10\%), Acinetobacter baumannii (6.6\%), Staphylococcus aureus and Citrobacter freundii (each of them $3.3 \%)$, Pseudomonas putida (2.2\%), and Klebsiella sp., Staphylococcus sp., Pseudomonas, Morganella morganii, Aeromonas sp., and Proteus mirabilis (each of them 1.1\%), respectively. It is in line with the research result by Myh and Manuputty where the result of urine culture was $(61.11 \%)$ positive in which it caused by E. coli $(14.8 \%)$.

Antibiotic sensitivity test is necessary to be conducted because sensitivity test is one method to determine bacteria vulnerability to the antibiotic . Antibiotic sensitivity test in RSUD (Regional Public Health) Prof. Dr. W. Z. Johannes Kupang conducted with disk-diffusion modification technique by Kirby-Bauer in which the requirements have been established by the WHO in 1976. This method is multipurpose method for all pathogens that grow rapidly. This method has adjusted to the fastidious bacteria as the most important clinically; however, it is not for obligate anaerobe and microbacteria. Antibiotic/antimicrobial sensitivity test assesses antimicrobial substance ability to inhibit the growth of in vitro bacteria [7].

Table 1: Age and gender distribution of UTI

\begin{tabular}{llll}
\hline \multirow{2}{*}{ Gender } & \multicolumn{2}{c}{ Total (\%) } & \multirow{2}{*}{ Total (\%) } \\
\cline { 2 - 3 } & Male (\%) & Female (\%) & \\
\hline$<10$ years & $4(13.3)$ & $4(7.0)$ & $8(9.1)$ \\
10-20 years & $5(16.6)$ & $3(5.2)$ & $8(9.1)$ \\
21-30 years & $1(3.3)$ & $7(12.2)$ & $8(9.1)$ \\
31-40 years & $4(13.3)$ & $11(19.2)$ & $15(17.2)$ \\
41-50 years & $7(23.3)$ & $7(12.2)$ & $14(16.0)$ \\
51-60 years & $2(6.6)$ & $9(15.7)$ & $11(12.6)$ \\
61-70 years & $2(6.6)$ & $12(21.0)$ & $14(16.0)$ \\
71-80 years & $4(13.3)$ & $3(5.2)$ & $7(8.0)$ \\
$>81$ years & $1(3.3)$ & $1(1.7$ & $2(2.2)$ \\
Total & $30(34.5)$ & $57(65.5)$ & $87(100 \%)$ \\
\hline
\end{tabular}

Table 2: Bacteria culture of urine

\begin{tabular}{ll}
\hline Bacteria culture of urine & Total (\%) \\
\hline Klebsiella sp. & $1(1.1)$ \\
K. pneumoniae & $12(13.3)$ \\
Enterobacteriaceae sp. & $7(7.7)$ \\
E. cloacae & $2(2.2)$ \\
E. sodiakii & $1(1.1)$ \\
E. aerogenes & $1(1.1)$ \\
Enterobacteriaceae & $6(6.6)$ \\
E. coli & $32(35.5)$ \\
S. aureus & $3(3.3)$ \\
Staphylococcus sp. & $1(1.1)$ \\
P. aeruginosa & $9(10)$ \\
P. putida & $2(2.2)$ \\
Pseudomonas & $1(1.1)$ \\
A. baumannii & $6(6.6)$ \\
C. freundii & $3(3.3)$ \\
M. morganii & $1(1.1)$ \\
Aeromonas sp. & $1(1.1)$ \\
P. mirabilis & $1(1.1)$ \\
Total & $90(100)$ \\
\hline
\end{tabular}

K. pneumonia: Klebsiella pneumonia, E. cloacae: Enterobacteriaceae cloacae, E. sodiakii: Enterobacteriaceae sodiakii, E. aerogenes: Enterobacteriaceae aerogenes, E. coli: Escherichia coli, S. aureus: Staphylococcus aureus,

P. aeruginosa: Pseudomonas aeruginosa, P. putida: Pseudomonas putida, A. baumannii: Acinetobacter baumannii, C. freundii: Citrobacter freundii, M. morganii: Morganella morganii, P. mirabilis: Proteus mirabilis 


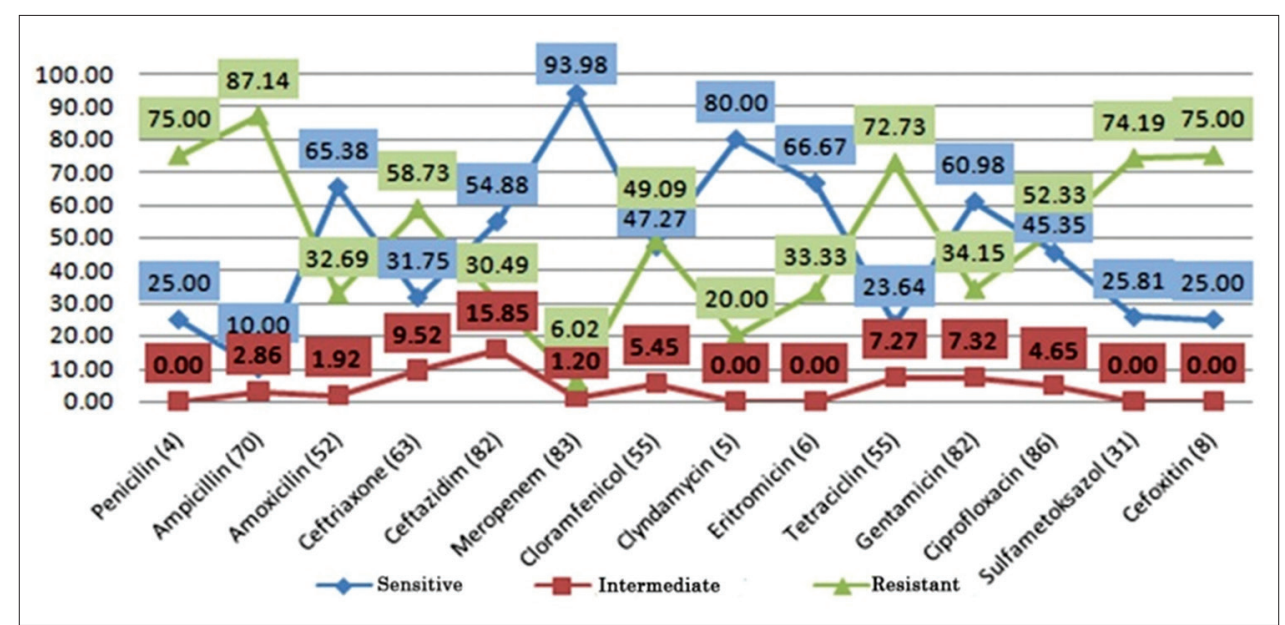

Fig. 1: Graph of percentage to the result of antibiotic sensitivity test in RSUD Prof. Dr. W. Z. Johannes Kupang during January 2013-December 2013

Meropenem is sensitive to the E. coli, Enterobacteriaceae, K. pneumoniae, and $P$. aeruginosa bacteria. Meropenem is beta-lactam antibiotic that effective for both Gram-negative and positive bacteria and has large spectrum. The obtained data in this research are suitable to the literature where meropenem is more effective for UTI that mostly caused by Gram-negative bacteria. It is also in line to the research result by Myh and Manuputty where from the result of sensitivity test, it is obtained that the most sensitive antibiotic for UTI is meropenem [8].

From the result of sensitivity test, it was obtained that the most resistance antibiotic is ampicillin (87.14\%), the second is penicillin and cefoxitin (each of them 75.0\%), the third is sulfamethoxazole (74.19\%), followed by tetracycline $(72.73 \%)$, ceftriaxone $(58.73 \%)$, ciprofloxacin (52.33\%), chloramphenicol (4.,09\%), gentamicin (34.15\%), erythromycin (33.33\%), amoxicillin (32,69\%), ceftazidime (30.49\%), clindamycin $(20 \%)$, and meropenem $(6.02 \%)$, respectively. Antibiotic resistance can be caused due to inappropriate time to use antibiotic, wrong dosage, continual use, and overused as well as misused antibiotic.

\section{CONCLUSION}

Based on the research result about the profile of antibiotic sensitivity to the patients with UTI in RSUD Prof. Dr. W. Z. Johannes Kupang, it can be concluded as follows:

1. The most widely used antibiotic is ciprofloxacin (98.8\%).
2. The most sensitive antibiotic is meropenem (93.98\%) to the E. coli, K. pneumoniae, and Enterobacteriaceae group bacteria. The most resistance antibiotic is ampicillin (87.14\%) to the E. coli, K. pneumoniae, Enterobacteriaceae, and C. freundii group bacteria.

\section{REFERENCES}

1. Mardiastuti A. Emerging resistance pathogen: Recent situation in Asia, Europe, USA, Middle East and Indonesia. Indones Med Mag 2009;57:3.

2. Herawati L. Study of Antibiotic Drug Usage in Urinary Tract Infection Patients. Surabaya: FF Airlangga; 2009.

3. Arifa DN. Sensitivity of Escherichia coli Generator Extended Spectrum Beta Lactamase (ESBL) against Carbapenem. Yogyakarta: Gadjah Mada University. UGM; 2014.

4. Wilianti L. Rationality of Antibiotic Usage in Urinary Tract Infections in Ward Disease in Dr. Kariadi Semarang Year 2008. Diponegoro University Thesis; 2009. p. 5-8.

5. Anonymous. Pharmaceutical Guidelines for Antibiotic Therapy. Jakarta: Kemenkes RI; 2011.

6. Corwin E. Pathophysiology Pocket Book. Jakarta: EGC; 2001.

7. Vandepitte D. Basic Laboratory Procedures for Clinical bacteriology. Jakarta: EGC; 2010.

8. Myh E, Manuputty D. Sensitivity and Resistant Pattern of Urin Germs. Jakarta: Catheter's Edge and Edge Drain Resipient Patients Transplate Kidney at RS PGI Cikini Journal of Andalas Health; 2012. 